\title{
Fibroblast Growth Factor 10 Plays a Causative Role in the Tracheal Cartilage Defects in a Mouse Model of Apert Syndrome
}

\author{
CATERINA TIOZZO, STIJN DE LANGHE, GIANNI CARRARO, DENISE AL ALAM, ANDRE NAGY, CLARENCE WIGFALL, \\ MOHAMMAD K. HAJIHOSSEINI, DAVID WARBURTON, PARVIZ MINOO, AND SAVERIO BELLUSCI
}

\begin{abstract}
Department of Pediatrics [C.T., P.M.], Women's and Children's Hospital, University of Southern California Keck School of Medicine, Los Angeles, California 90033; Department of Pediatrics [S.L.], National Jewish Health, Denver, Colorado 80238; Department of Surgery, Developmental Biology Program [G.C., D.A.A., A.N., C.W., D.W., S.B.], Saban Research Institute of Children's Hospital Los Angeles, Los Angeles, California 90027; School of Biological Sciences [M.K.H.], University of East Anglia (UEA), Norwich, Norfolk, NR4 7TJ,
\end{abstract} United Kingdom

\begin{abstract}
Patients with Apert syndrome (AS) display a wide range of congenital malformations including tracheal stenosis, which is a disease characterized by a uniform cartilaginous sleeve in place of a normally ribbed cartilagenous trachea. We have studied the cellular and molecular basis of this phenotype in a mouse model of AS ( $F g f r 2 c^{+/ \Delta}$ mice), which shows ectopic expression of $F g f r 2 b$ in mesenchymal tissues. Here we report that tracheal stenosis is associated with increased proliferation of mesenchymal cells, where the expression of FgflO and its upstream regulators $T b \times 4$ and $T b \times 5$ are abnormally elevated. We show that $F g f 10$ has a critical inductive role in tracheal stenosis, as genetic knockdown of $\mathrm{FgflO}$ in $\mathrm{Fgfr} 2 \mathrm{c}^{+/ \Delta}$ mice rescues this phenotype. These novel findings demonstrate a regulatory role for FgflO in tracheal development and shed more light on the underlying cause of tracheal defects in AS. (Pediatr Res 66: 386-390, 2009)
\end{abstract}

$\mathrm{T}^{\mathrm{s}}$ he laryngotracheal groove arises from the floor of the primitive pharynx at around E9.5 in mice, and the trachea and the two primitive lung buds differentiate from this primitive lung anlagen. The rudimentary trachea is a tube composed of epithelial cells derived from the foregut endoderm and surrounded by splanchnic mesenchyme. During embryonic development, appropriate dorsoventral patterning of the trachea leads to the differential formation of cartilage on the ventral side and smooth muscle on the dorsal side. In addition, the ventral mesenchyme differentiates into a succession of cartilaginous and noncartilagenous domains, allowing the mature trachea to be flexible along its dorsoventral axis, yet resistant to collapse. However, the genetic control of mesenchymal differentiation along the tracheal dorsoventral axis and the regulation of cartilage versus smooth muscle cell formation are still unclear. Defects in the formation of these two specialized tissues along the proximal-distal and dorsoventral axes result in severe tracheal malformations, such as tracheomalacia and stenosis.

Received April 27, 2009; accepted June 14, 2009.

Correspondence: Saverio Bellusci, Ph.D., Saban Research Institute of Childrens Hospital Los Angeles, Developmental Biology Program, 4650 W. Sunset Blvd., Mail Stop 35, Los Angeles, CA 90027; e-mail: sbellusci@chla.usc.edu

Supported by Grant 1R01HL086322 from European Society of Pediatrics (to S.B.);

Young Investigator Grant (to C.T.); and CIRM Clinical Fellowship (to C.T.).

Caterina Tiozzo and Stjin De Langhe contributed equally to this work.
Tracheal stenosis is a rare condition leading to the narrowing of the lumen of the trachea. It involves the formation of a uniform tracheal cartilaginous sleeve, affecting either a subset or the entire set of cartilaginous rings found in a normal trachea. Tracheal stenosis may occur as an isolated anomaly but is most often associated with other malformations present in several congenital syndromes, including bridging bronchus and sling pulmonary artery (1).

One of these is Apert syndrome (AS), which occurs at a rate of one per 65,000 live births as an autosomal dominant trait. In most cases AS arises from de novo mutations that originate from the father and appears to correlate with increased paternal age $(2,3)$. AS is characterized by severe syndactyly of feet and hands, craniofacial abnormalities, and craniosynostosis, in addition to stridor and pneumonia or both in the first few months of life (4). Indeed, most AS sufferers experience upper airway obstruction secondary to craniofacial abnormalities. Many may have sleep apnea and also present anomalous tracheal cartilage that can cause early death through severe lower airway obstruction (5).

AS arises through gain-of-function mutations in the fibroblast growth factor (FGF) receptor 2 (FGFR2), all of which act in a ligand-dependant manner and result in excessive FGFR2 activity in the mesenchyme (6-10). Recently, mice that harbor a gain-of-FGFR2 signaling defect with AS symptoms (11) have been described and allow for a better understanding of the molecular basis of AS pathology (12). These mice display increased mesenchymal FGF signaling and a range of skeletal, visceral, and neuronal defects that are hallmarks of AS.

Thus far, ethical and practical reasons have precluded a detailed characterization of the precise range and type of AS-associated defects both within and among patients. Hence, information is derived mostly from postmortem analysis. Moreover, subtle defects in the affected children may have been overlooked or may not have been readily ascertainable from crude scans. Visceral defects, such as those of the trachea, contribute to the pathology either under normal con-

\footnotetext{
Abbreviations: AS, Apert syndrome; E13.5, embryonic day 13.5 post coitum; FGF, fibroblast growth factor; FGFR, fibroblast growth factor receptor; $\mathbf{P 0}$, postnatal day 0
} 

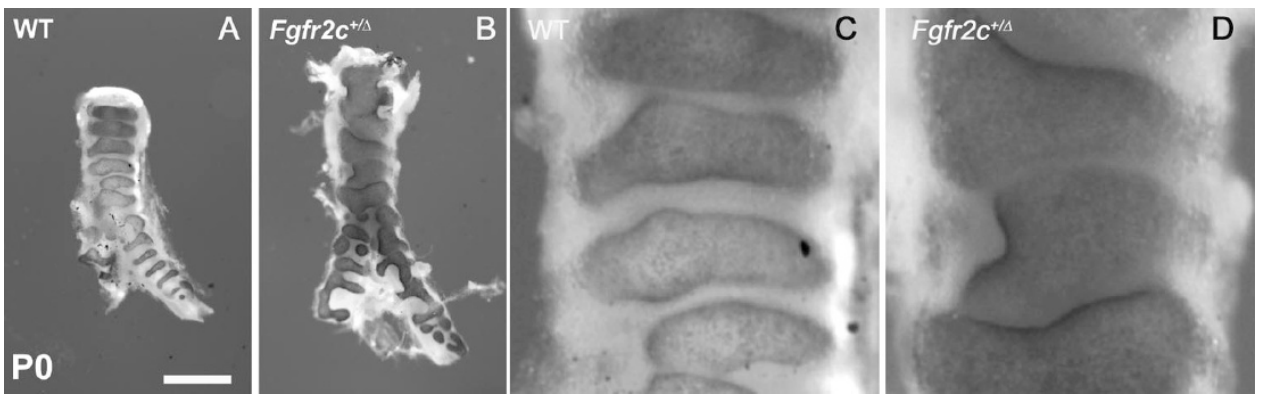

Figure 1. Excessive mesenchymal FGF signaling leads to overgrowth of the tracheal rings. WT and mutant tracheas are stained with alcian blue. A, WT trachea at P0 exhibiting regular cartilage rings separated by noncartilaginous mesenchyme; $B, F g f r 2 c^{+/ \Delta}$ trachea at $\mathrm{P} 0$ showing excessive growth of the cartilage with absence of noncartilaginous mesenchyme. $C, D$, Higher magnification of $A$ and $B$, respectively. Scale bar $(A, B): 160 \mu \mathrm{m} ;(C, D)$ : $32 \mu \mathrm{m}$.

ditions or, for example, during anesthesia for corrective skeletal surgery (13). The precise type of lung pathology that we observe in our mouse model has been described in patients with AS $(6,7)$, namely the fusion of tracheal cartilage rings, pulmonary hypoplasia, defects in interlobular septation, and absence of the accessory lobe (14). However, the molecular interactions that bring about these subtle upper and lower respiratory tract defects have remained completely unknown until this time. In this article, we clarify the causative role of FGF10 in the tracheal phenotype present in AS.

In mammals, four FGFR have been identified (FGFR1 to FGFR4), each comprising an extracellular region composed of two or three immunoglobulin-like (Ig) domains, a transmembrane segment, and an intracellular tyrosine kinase domain $(15,16)$. Alternative splicing of the exons that encode the C-terminal half of the third Ig domain in FGFRs-1, -2, and -3 results in receptor isoforms termed "IIIb" or "IIIc," each with respectively distinct ligand-binding specificity and tissue distributions (17). The Fgfr2 gene splice variant containing the IIIb exon $(F g f r 2 b)$ is expressed mainly in epithelia, and the corresponding receptor is activated by four known ligands, FGFs-1, 3, 7, and 10, which are synthesized predominantly within the mesenchyme. In contrast, FGFR2-IIIc $(F g f r 2 c)$ is located primarily in the mesenchyme, and in addition to FGF1, is activated by a different set of FGF ligands, FGFs-2, $4,6,8,9$, and $18(16,18-22)$.

FGF10 is the primary ligand for FGFR2b during embryonic development as demonstrated by the remarkable similarity of phenotypes exhibited by embryos where these genes have been inactivated (23-25). In the lung, FGF10 has been associated with instructive mesenchymal-epithelial interactions, such as those that occur during epithelial morphogenesis, and with the control of the directional outgrowth of lung buds during branching morphogenesis (22). Furthermore, FGF10 was shown to induce chemotaxis of the distal lung epithelium $(8,26)$. Using a combination of multiple experimental approaches, such as gene expression analysis, cell proliferation quantification, and genetic epistasis, to analyze the consequences of increased mesenchymal FGFR2 signaling in the trachea, we demonstrate for the first time that FgflO is expressed in the tracheal mesenchyme and plays a causative role in the cartilage abnormalities observed in our mouse model of AS.

\section{MATERIALS AND METHODS}

Transgenic embryos. Mice $F g f r 2 c^{+/ \Delta}$ were generated as previously described (11). All the animal studies were approved by the Institutional Animal Care and Use Committee (IACUC) at Children's Hospital Los Angeles. The mice were maintained in an outbred background, in accordance with the institutional regulations. Male mice harboring the floxed allele were crossed with heterozygous $C M V$-Cre female mice, which are expressing the Cre recombinase in the germ cells (Jackson Laboratories).

In situ hybridization. Whole mount in situ hybridization (WMISH) was performed on E13.5 embryonic tracheas as previously described (14).

Immunohistochemistry. Embryonic tracheas from different stages were dissected, fixed overnight in $4 \%$ paraformaldehyde, rinsed with PBS three times for $10 \mathrm{~min}$, dehydrated with increasing concentrations of ethanol, submerged in xylene, and embedded in paraffin blocks. Sections of $5 \mu \mathrm{m}$ were cut and stained for the following antibodies with the previously described protocol (14): phosphohistone H3 (Cell signaling, 1:200) and collagen 2 (Millipore, 1:200)

The slides were mounted with Vectashields (Vector Labs) containing 4'-6-diamidino-2-phenylindole (DAPI). Photographs were taken using a Leica DMRA fluorescence microscope with a Hamamatsu Digital CCD camera.

Alcian blue staining. The slides were deparaffinized and hydrated with distilled water, stained in alcian blue solution for $30 \mathrm{~min}$. After washing them in water for $2 \mathrm{~min}$, the slides were dehydrated with ethanol, cleared in xylene, and mounted with mounting medium.

Data presentation and statistical analysis. Data were presented as mean \pm SD unless otherwise stated. Statistical analyses were performed on the data with ANOVA test for comparison of two groups, and $p$ values $\leq 0.05$ were considered as significant.

\section{RESULTS}

$\mathrm{Fgfr}_{2} \mathrm{c}^{+/ \Delta}$ tracheas exhibit expansion of the tracheal cartilaginous rings. The skeletal and branching defects in the lungs and submandibular glands of $F g f r 2 c^{+/ \Delta}$ mice have been previously described $(11,14,27)$. To investigate potential tracheal defects, we generated $F g f r 2 c^{+/ \Delta}$ mice by intercrossing $C M V$-cre heterozygous mice with $F g f r 2 c^{f l o x}$ flox mice to generate $\left[C M V\right.$-cre $\left.; F g f r 2 c^{+/ \Delta}\right]$. A by-product of this cross was $F g f r 2 c^{f l o x /+}$ embryos, which were phenotypically indistinguishable from wild type (WT) control embryos. The results of this study thereby indicate that $F g f r 2 c^{+/ \Delta}$ mice do display several tracheal anomalies that take place during organogenesis.

Alcian blue staining was performed to visualize the mature cartilaginous rings in WT and mutant tracheas. At birth, WT tracheas exhibit well-defined cartilage rings separated by noncartilaginous mesenchyme (Fig. $1 A$ and $C$ ). $F g f r 2 c^{+/ \Delta}$ tracheas at $\mathrm{P} 0$ show a fusion of cartilage rings, suggestive of excessive growth of the cartilage (Fig. $1 B$ and $D$ ). In E14.5 control trachea, immunohistochemistry for collagen 2 , a specific maker of chondrocytes, highlights the mesenchymal condensation, which will form the future cartilage rings (Fig. 2A). In the mutant trachea, by contrast, collagen 2 expression was spread out without condensation into specific structures (Fig. 2B).

Analysis of proliferation at embryonic day E13.5 shows that mutant tracheas have increased proliferation in the mesenchyme compared with WT tracheas, as assessed by phospho- 
histone $\mathrm{H} 3$ staining $(2 \pm 1 \%$ versus $5 \pm 0.9 \%$, respectively; $p<0.01$; Graph 1; Fig. $2 C$ and $D$ ). Based on our previous published results, this is attributable to the mesenchyme now being competent to respond to FGF10 and, therefore, receiving increased levels of FGF signaling. These data also show that increased mesenchymal FGF signaling leads to increased cartilage formation, similar to what is observed in AS.

Increased levels of mesenchymal FGF signaling upregulate Tbx4 and Fgf10 expression. We have previously shown that increased levels of mesenchymal FGF signaling in

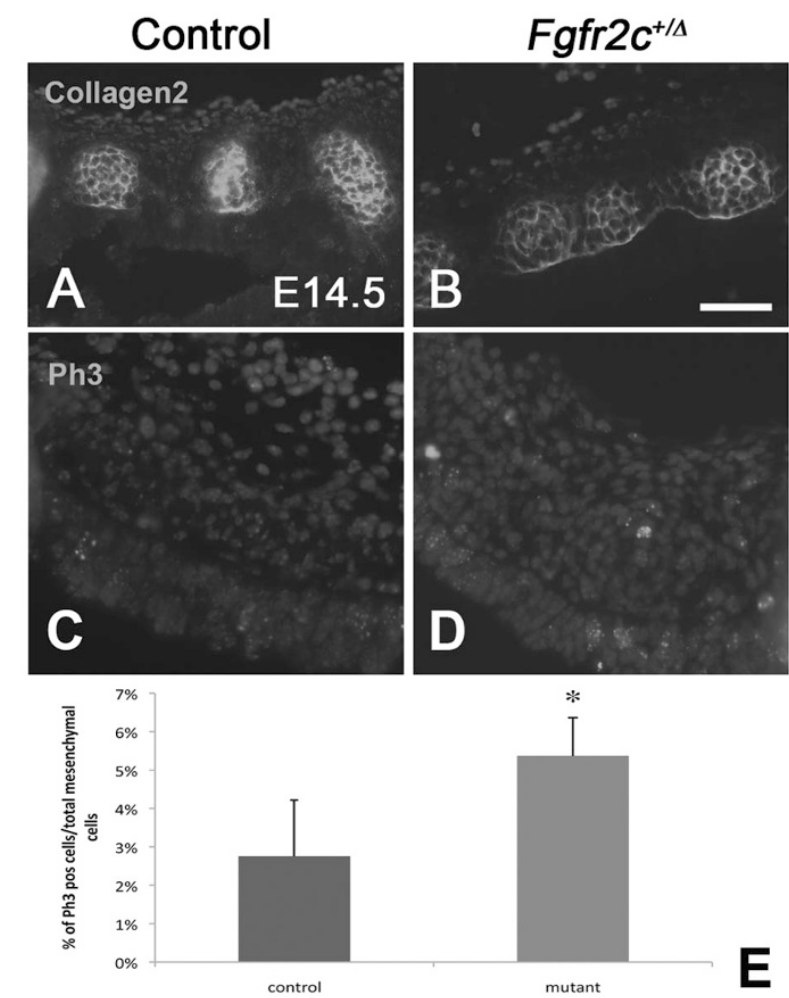

Figure 2. Collagen 2 expression and proliferation rate in $\mathrm{Fgfr} 2 \mathrm{c}^{+/ \Delta}$ compared with control E14.5 tracheas. Immunohistochemistry for collagen 2 in WT (A) and $F g f r 2 c^{+/ \Delta}$ trachea $(B)$, showing the lack of distinct cartilaginous and noncartilaginous domains in mutant tracheas. Analysis of proliferation assessed by PH3 labeling $(C, D)$, showing increased of proliferation in the mutant compared with the WT $(E) . n=3$ each group; $p<0.01$. Scale bar $(A$, $B): 120 \mu \mathrm{m} ;(C, D): 100 \mu \mathrm{m}$. the lung result in an up-regulation in $F g f 10$ expression in the distal lung mesenchyme (14). Therefore, we examined $F g f r 2 b$ and $F g f 10$ expression in the trachea. $F g f r 2 b$ was expressed in the WT epithelium at E13.5 (Fig. 3A), whereas in the mutant, $F g f r 2 b$ was present in the epithelium and was ectopically expressed in the mesenchyme (Fig. $3 B$ ).

In the WT trachea, we show that Fgfl0 is expressed at low but significant levels in the ventral mesenchyme, which gives rise to the cartilage rings (Fig. $4 A$ and $B$ ). Interestingly, as in the lung mesenchyme, we found that $F g f 10$ was up-regulated in ventral mesenchyme of the $F g f r 2 c^{+/ \Delta}$ trachea (Fig. $4 C$ and $D$ ).

To understand the mechanisms responsible for FgflO upregulation, we studied $T b x 4$ and $T b x 5$, two members of the T-box transcription factor gene family, which are specifically expressed in the visceral mesoderm of the lung primordium and are upstream of $F g f l 0$ expression. Tbx4 expression was specifically increased in the mutant trachea compared with the WT control at E13.5 (Fig. $4 E$ and $F$ ). Moreover, Tbx5 expression showed a segmented pattern of expression in the WT trachea, whereas in the mutant, the expression was present as a continuous sleeve, without any sign of segmentation (Fig. $3 C, C^{\prime}, D$, and $\left.D^{\prime}\right)$.

We further found down-regulation of epithelial $W n t 7 b$ expression in $\mathrm{Fgfr} 2 \mathrm{C}^{+/ \Delta}$ tracheas compared with WT tracheas (Fig. $3 E, E^{\prime}, F$, and $F^{\prime}$ ), suggesting a decrease in Wnt signaling, similar to our observations in the lung (14).

Overall, these results suggest the development of an aberrant FGF10/FGFR2b autocrine feedback loop maintaining high levels of $F g f 10$ expression in $F g f r 2 c^{+/ \Delta}$ tracheal ventral mesenchyme, likely via the up-regulation of $T b \times 4$ and $T b \times 5$ expression. The causative role of FgflO in the tracheal ring abnormalities was demonstrated as shown in the following section of this article using an in vivo genetic epistasis approach.

Heterozygous knock down of Fgf10 expression rescues the tracheal cartilage fusion phenotype in $\mathrm{Fg} f \mathrm{r} 2 \mathrm{c}^{+/ \Delta}$ mice. Misexpression of $F g f r 2 b$ in the tracheal mesenchyme leads to the development of an aberrant FGF10/FGFR2b autocrine feedback loop maintaining high levels of $F g f l 0$ signaling in the mesenchyme. To test whether decreasing $F g f 10$ expression in vivo would rescue the tracheal phenotype, we crossed

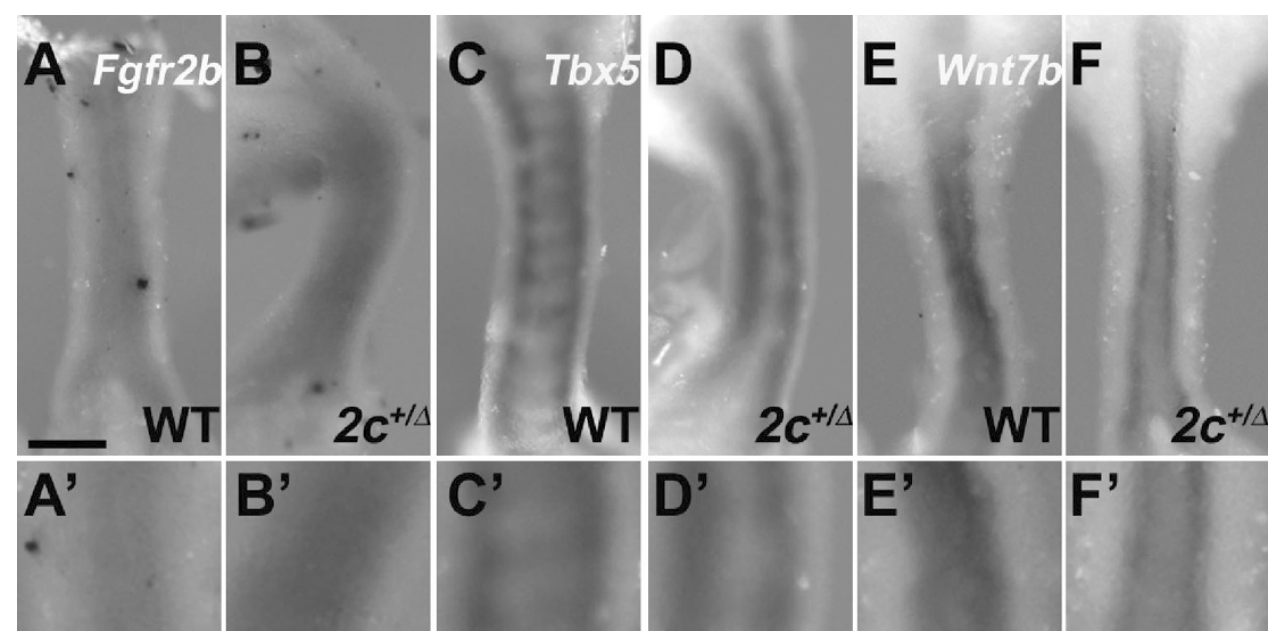

Figure 3. Abnormal cartilage patterning is detected as early as E13.5. WMISH for Fgfr2-IIIb (A), Tbx5 (C), and Wnt7b (E) in WT and in $F g f r 2 c^{+/ \Delta}(B, D$, and $F)$ E13.5 tracheas. A, Fgfr2-IIIb is detected in the epithelium in WT trachea; $B$, As expected, Fgfr2-IIIb is also detected in the mesenchyme in Fgfr $2 c^{+/ \Delta}$ tracheas; C, A segmented pattern of expression is observed for $T b x 5$ in WT trachea; $D$, An altered segmented pattern is visible in $\mathrm{Fg} f \mathrm{r} 2 \mathrm{c}^{+/ \Delta}$ tracheas. A similar observation is made for $W n t 7 b(E, F) . A^{\prime}-F^{\prime}$, Higher magnification of $A-F$, respectively. Scale bar $(A-F): 50$ $\mu \mathrm{m}$. $\left(\mathrm{A}^{\prime}-\mathrm{F}^{\prime}\right): 25 \mu \mathrm{m}$. 
$\left[C M V\right.$-cre $\left.; \mathrm{FgflO}^{ \pm}\right]$mice with $\mathrm{Fgfr} 2 \mathrm{c}^{\text {flox/flox }}$ mice to generate $\left[\mathrm{CMV}\right.$-cre; Fgfr $\left.2 c^{+/ \Delta} ; \mathrm{FgflO}{ }^{ \pm}\right]$and [CMV-cre; Fgfr $2 c^{+/ \Delta}$; $\mathrm{FgflO}^{+/+}$] (equivalent to $\mathrm{Fgfr} 2 \mathrm{c}^{+/ \Delta}$ ) mice. At P0, Fgfr $2 c^{+/ \Delta}$ tracheas manifest an excessive expansion of the cartilage with absence of noncartilaginous mesenchyme (Fig. $5 A$ and $C$ ). $\left[\mathrm{CMV}\right.$-cre; Fgfr $\left.2 \mathrm{c}^{+/ \Delta} ; \mathrm{FgflO}{ }^{ \pm}\right]$neonate tracheas, however, show a rescue of the tracheal defects with presence of welldefined cartilaginous rings (Fig. $5 B$ and $D$ ). These data demonstrate for the first time the causative role of FgflO in abnormal tracheal cartilaginous rings formation.

\section{DISCUSSION}

AS arises through mutations in the Fgfr 2 gene, all of which result in gain-of-FGFR2 activity in the mesenchyme leading to multiple skeletal and visceral defects (7). The Fgfr $2 c$ splicing defect present in the $F g f r 2 c^{+/ \Delta}$ mice is the same as a rare Apert-causing FGFR2c mutation in humans (28). In these mice, the exon IIIc was removed: $760 \mathrm{bp}$ at the level of the upstream intron and $440 \mathrm{bp}$ in the downstream intron. In the heterozygous state, these mice present a phenotype whose severity and range is very similar to mice harboring a more common human Apert mutation $\left(F G F R 2^{+/ S 252 \mathrm{~W}}\right)$, as well as the mice being similar to the patients affected by AS (29).

Recently, the same type of mutation leading to a splicing defect with ectopic FGFR2b expression in the mesenchyme was described in a human patient: a deletion of approximately $1930 \mathrm{bp}$ of exon IIIc and the flanking introns was detected in a patient affected by imperforate anus, bilateral coronal and

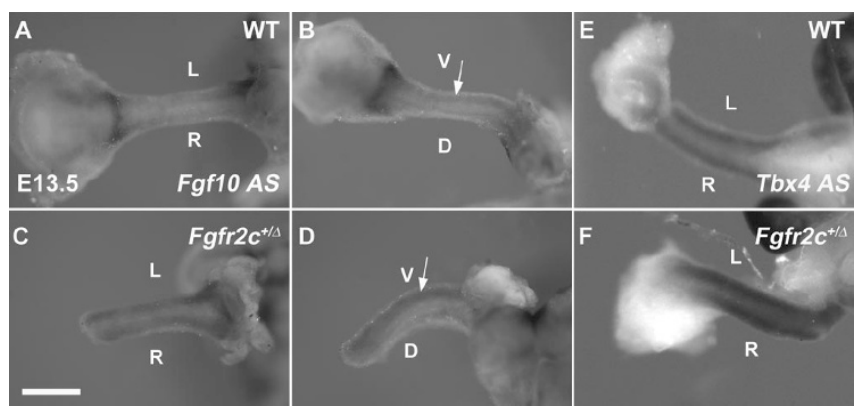

Figure 4. FgflO and $\mathrm{Tbx} 4$ expression are increased in $F g f r 2 c^{+/ \Delta}$ tracheas at E13.5. Ventral $(A, C)$ and lateral $(B, D)$ views of WT $(A, B)$ and $(C, D)$ $F g f r 2 c^{+/ \Delta}$ E13.5 tracheas labeled for FgflO transcript. Note that FgflO is expressed at low but significant levels in the ventral mesenchyme of the WT trachea. This expression is increased in the $F g f r 2 c^{+/ \Delta}$ trachea. An increase in $T b x 4$ expression is also observed in the $F g f r 2 c^{+/ \Delta}$ E13.5 tracheas $(E, F) . L$, left; $R$, right; $V$, ventral; $D$, dorsal. Scale bar $(A-F): 75 \mu \mathrm{m}$.
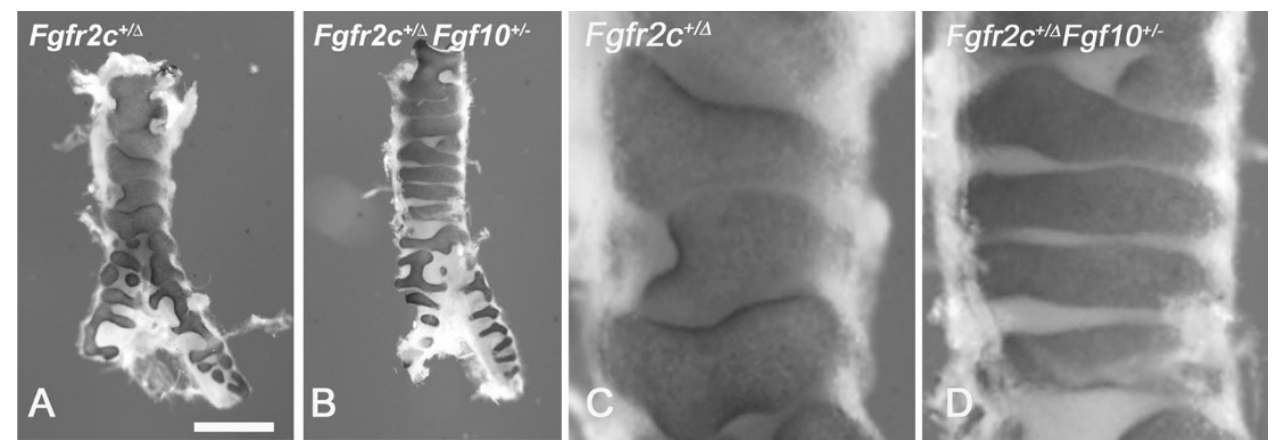

lambdoid synostosis, syndactyly, developmental delay with focal epilepsy, and tracheal cartilagenous sleeve (28). Interestingly, this patient displays the same tracheal phenotype as in our mouse model, suggesting a link between this type of genetic mutation and the tracheal phenotype described in both mice and humans.

Three recent reports described the contribution of the FGFR2b/ FGF10 pathway to the AS phenotype using $F g f r 2 c^{+/ \Delta}$ mice harboring heterozygous deletion of an Fgfr $2 c$ exon. The first study reported the characterization of these mice and described visceral and bone defects similar to those present in the AS with fusion of the coronal and facial sutures, premature ossification of sternal bones, perturbation of neurogenesis in the brain, and branching morphogenesis defects in several visceral organs (11). In the second report, describing the contribution of FGFR2b/FGF10 pathway to the AS phenotype using $F g f r 2 c^{+/ \Delta}$ mice harboring heterozygous deletion of Fgf2-IIIc exon, we demonstrated that these mice exhibit a complex lung phenotype consisting of absence of the accessory lobe, defective interlobular septation, and dilated airways secondary to abundant mesenchyme (14). These defects were secondary to the ectopic expression of $F g f r 2 b$ in the mesenchyme leading to the formation of an FGF10/FGFR2b autocrine feedback loop, which maintained the progenitors for the parabronchial smooth muscle cells to locate within the submesothelial mesenchyme in an undifferentiated state (24).

The most recent study (30) proved that reduction of FgflO rescues the skeletal and lung defects; however, the tracheal defects have never been investigated before. In all organs studied in these reports, there was a direct causative relation between high levels of FgflO overexpression and the observed phenotype, whereas heterozygous knockdown of FgflO levels partially rescued the phenotype.

Our work indicates that at the tracheal level, the same FGF10/FGFR2b loop is detected. Ectopic expression of FGFR2b in the paratracheal mesenchyme, therefore, renders this compartment hyperresponsive to FGF10, whereas heterozygous knockdown in FgflO levels completely rescues the phenotype.

We also observed a reduction in $W n t 7 b$ expression in the mutant trachea (Fig. $3 E-F^{\prime}$ ). It has been reported that Wnt signaling is essential in determining whether mesenchymal progenitors will become osteoblasts or chondrocytes (31). Our results showing a decrease in $W n t 7 b$ in the mutant trachea, therefore, suggest that in addition to excessive proliferation of the mesenchymal progenitors, there is also a potential defect
Figure 5. Heterozygous knockdown of Fgf10 levels partially rescues the tracheal cartilage phenotype of $\mathrm{Fg} F \mathrm{r} 2 \mathrm{c}^{+/ \Delta}$ lungs. A, $\mathrm{Fgfr}_{\mathrm{C}} \mathrm{C}^{+/ \Delta}$ trachea at $\mathrm{P} 0$ showing excessive expansion of the cartilage with absence of noncartilaginous mesenchyme. $B,\left[F g f r 2 c^{+1}\right.$ $\left.{ }^{\Delta} ; \mathrm{FgflO}^{ \pm}\right]$neonates tracheas show a rescue of the tracheal defects. $C$ and $D$, higher magnification of $A$ and $B$, respectively. Scale bar $(A, B): 160 \mu \mathrm{m} ;(C, D): 32 \mu \mathrm{m}$. 
in their differentiation. The role of FGF signaling in the mesenchyme of the lung and trachea is quite novel. We have published that FGF signaling in the mesenchyme controls positive survival and proliferation, whereas inhibiting differentiation $(14,32)$. In addition, we have recently published that inactivation of beta-catenin in the mesenchyme leads to abnormal lung development with isomerization of the lung, reduced branching, and shortened trachea as well as defective amplification of mesenchymal progenitors for the parabronchial smooth muscle cells (33). Based on these results, we propose therefore that FGF10 signaling in the mesenchyme, in this model of AS, acts upstream of beta-catenin signaling to control the expression of Fgfr2, cMyc, and Tbx4.

Thus, we conclude that a normal FgflO expression level is a necessary component for the tracheal cartilage formation and gain-of-function disruption of this pathway leads to aborted cartilaginous rings that mimic the tracheal AS-like phenotype. The normal function of FgflO in tracheal formation is currently being investigated using a loss-of-function approach. Our preliminary results indicate indeed that $F g f l 0$ is critical for the patterning of the tracheal rings (Sala and Bellusci, unpublished results). The data therefore validate functionally the expression of FgflO in the tracheal mesenchyme both in normal and pathologic situations.

In summary, our study describes for the first time the molecular basis of the tracheal phenotype in our mouse model of AS: a FGF10/FGFR2b gain-of-function is responsible for the formation of a tracheal cartilage sleeve secondary to an increase in the proliferation of the tracheal cartilage progenitor cells in the mesenchyme. Conversely, decreased FgflO expression rescues the tracheal cartilage fusion phenotype, confirming the causative role of FgflO in this pathology and opening the way for possible development of therapeutic interventions aimed at interfering with FGF10 signaling.

\section{REFERENCES}

1. Wells TR, Stanley P, Padfua EM, Landing BH, Warburton D 1990 Serial sectionreconstruction of anomalous tracheobronchial branching patterns from CT scan images: bridging bronchus associated with sling left pulmonary artery. Pediatr Radiol 20:444-446

2. Moloney DM, Slaney SF, Oldridge M, Wall SA, Sahlin P, Stenman G, Wilkie AO 1996 Exclusive paternal origin of new mutations in Apert syndrome. Nat Genet $13: 48-53$

3. Glaser RL, Jiang W, Boyadjiev SA, Tran AK, Zachary AA, Van Maldergem L, Johnson D, Walsh S, Oldridge M, Wall SA, Wilkie AO, Jabs EW 2000 Paternal origin of FGFR2 mutations in sporadic cases of Crouzon syndrome and Pfeiffer syndrome. Am J Hum Genet 66:768-777

4. O'Neill JA, Rowe MI, Grosfeld JL, Fonkalsrud EW, Coran AG 1998 Pediatric Surgery, C.V. Mosby Co, St. Louis, MO, pp 869

5. Papay FA, McCarthy VP, Eliachar I, Arnold J 2002 Laryngotracheal anomalies in children with craniofacial syndromes. J Craniofac Surg 13:351-364

6. Cohen MM Jr, Kreiborg S 1992 Upper and lower airway compromise in the Apert syndrome. Am J Med Genet 44:90-93

7. Cohen MM Jr, Kreiborg S 1993 Visceral anomalies in the Apert syndrome. Am J Med Genet 45:758-760

8. Park WJ, Theda C, Maestri NE, Meyers GA, Fryburg JS, Dufresne C, Cohen MM Jr, Jabs EW 1995 Analysis of phenotypic features and FGFR2 mutations in Apert syndrome. Am J Hum Genet 57:321-328
9. Wilkie AO, Slaney SF, Oldridge M, Poole MD, Ashworth GJ, Hockley AD, Hayward RD, David DJ, Pulleyn LJ, Rutland P, Malcolm S, Winter RM, Reardon W 1995 Apert syndrome results from localized mutations of FGFR2 and is allelic with Crouzon syndrome. Nat Genet 9:165-172

10. Hajihosseini MK 2008 Fibroblast growth factor signaling in cranial suture development and pathogenesis. Front Oral Biol 12:160-177

11. Hajihosseini MK, Wilson S, De Moerlooze L, Dickson C 2001 A splicing switch and gain-of-function mutation in FgfR2-IIIc hemizygotes causes Apert/Pfeiffersyndrome-like phenotypes. Proc Natl Acad Sci U S A 98:3855-3860

12. Yu K, Ornitz DM 2001 Uncoupling fibroblast growth factor receptor 2 ligand binding specificity leads to Apert syndrome-like phenotypes. Proc Natl Acad Sci U S A 98:3641-3643

13. Elwood T, Sarathy PV, Geiduschek JM, Ulma GA, Karl HW 2001 Respiratory complications during anaesthesia in Apert syndrome. Paediatr Anaesth 11:701-703

14. De Langhe SP, Carraro G, Warburton D, Hajihosseini MK, Bellusci S 2006 Levels of mesenchymal FGFR2 signaling modulate smooth muscle progenitor cell commitment in the lung. Dev Biol 299:52-62

15. Johnson DE, Williams LT 1993 Structural and functional diversity in the FGF receptor multigene family. Adv Cancer Res 60:1-41

16. McKeehan WL, Wang F, Kan M 1998 The heparan sulfate-fibroblast growth factor family: diversity of structure and function. Prog Nucleic Acid Res Mol Biol 59:135-176

17. Ornitz DM, Xu J, Colvin JS, McEwen DG, MacArthur CA, Coulier F, Gao G, Goldfarb M 1996 Receptor specificity of the fibroblast growth factor family. J Biol Chem 271:15292-15297

18. Peters KG, Werner S, Chen G, Williams LT 1992 Two FGF receptor genes are differentially expressed in epithelial and mesenchymal tissues during limb formation and organogenesis in the mouse. Development 114:233-243

19. Orr-Urtreger A, Bedford MT, Burakova T, Arman E, Zimmer Y, Yayon A, Givol D, Lonai P 1993 Developmental localization of the splicing alternatives of fibroblast growth factor receptor-2 (FGFR2). Dev Biol 158:475-486

20. Mason I 1994 Cell signalling. Do adhesion molecules signal via FGF receptors? Curr Biol 4:1158-1161

21. Yamasaki M, Miyake A, Tagashira S, Itoh N 1996 Structure and expression of the rat mRNA encoding a novel member of the fibroblast growth factor family. J Biol Chem 271:15918-15921

22. Bellusci S, Grindley J, Emoto H, Itoh N, Hogan BL 1997 Fibroblast growth factor 10 (FGF10) and branching morphogenesis in the embryonic mouse lung. Development 124:4867-4878

23. De Moerlooze L, Spencer-Dene B, Revest JM, Hajihosseini M, Rosewell I, Dickson C 2000 An important role for the IIIb isoform of fibroblast growth factor receptor 2 (FGFR2) in mesenchymal-epithelial signalling during mouse organogenesis. Development 127:483-492

24. Mailleux AA, Tefft D, Ndiaye D, Itoh N, Thiery JP, Warburton D, Bellusci S 2001 Evidence that SPROUTY2 functions as an inhibitor of mouse embryonic lung growth and morphogenesis. Mech Dev 102:81-94

25. Ohuchi H, Hori Y, Yamasaki M, Harada H, Sekine K, Kato S, Itoh N 2000 FGF10 acts as a major ligand for FGF receptor 2 IIIb in mouse multi-organ development. Biochem Biophys Res Commun 277:643-649

26. Weaver M, Dunn NR, Hogan BL 2000 Bmp4 and Fgf10 play opposing roles during lung bud morphogenesis. Development 127:2695-2704

27. Jaskoll T, Zhou YM, Chai Y, Makarenkova HP, Collinson JM, West JD, Hajihosseini MK, Lee J, Melnick M 2002 Embryonic submandibular gland morphogenesis: stage-specific protein localization of FGFs, BMPs, Pax6 and Pax9 in normal mice and abnormal SMG phenotypes in FgfR2-IIIc $(+/ \Delta)$, BMP7 $(-/-)$ and Pax6(-/-) mice. Cells Tissues Organs 170:83-98

28. Bochukova EG, Roscioli T, Hedges DJ, Taylor IB, Johnson D, David DJ, Deininger PL, Wilkie AO 2009 Rare mutations of FGFR2 causing Apert syndrome: identification of the first partial gene deletion, and an Alu element insertion from a new subfamily. Hum Mutat 30:204-211

29. Wang Y, Xiao R, Yang F, Karim BO, Iacovelli AJ, Cai J, Lerner CP, Richtsmeier JT, Leszl JM, Hill CA, Yu K, Ornitz DM, Elisseeff J, Huso DL, Jabs EW 2005 Abnormalities in cartilage and bone development in the Apert syndrome FGFR2 $(+1$ S252W) mouse. Development 132:3537-3548

30. Hajihosseini MK, Duarte R, Pegrum J, Donjacour A, Lana-Elola E, Rice DP, Sharpe J, Dickson C 2009 Evidence that Fgf10 contributes to the skeletal and visceral defects of an Apert syndrome mouse model. Dev Dyn 238:376-385

31. Day TF, Guo X, Garrett-Beal L, Yang Y $2005 \mathrm{Wnt} / \beta$-catenin signaling in mesenchymal progenitors controls osteoblast and chondrocyte differentiation during vertebrate skeletogenesis. Dev Cell 8:739-750

32. del Moral PM, De Langhe SP, Sala FG, Veltmaat JM, Tefft D, Wang K, Warburton D, Bellusci S 2006 Differential role of FGF9 on epithelium and mesenchyme in mouse embryonic lung. Dev Biol 293:77-89

33. De Langhe SP, Carraro G, Tefft D, Li C, Xu X, Chai Y, Minoo P, Hajihosseini MK, Drouin J, Kaartinen V, Bellusci S 2008 Formation and differentiation of multiple mesenchymal lineages during lung development is regulated by $\beta$-catenin signaling. PLoS One 3:e1516 